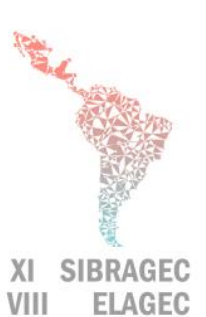

VIII ELAGEC
XI SIMPÓSIO BRASILEIRO DE GESTÃO E ECONOMIA DA CONSTRUÇÃO

VIII ENCUENTRO LATINOAMERICANO DE GESTIÓN Y ECONOMÍA DE LA CONSTRUCCIÓN

Do conhecimento à ação: práticas avançadas de gestão da produção Londrina, Paraná, Brasil. 23 a 25 de Outubro de 2019

\title{
ESTUDO DE CASO DA APLICAÇÃO DO RDC EM OBRA PÚBLICA DE INFRAESTRUTURA
}

\author{
ZACARIAS, Leonardo Gottschalg (1); ANDERY, Paulo Roberto Pereira (2); \\ STARLING, Cicero Murta Diniz (3); LOURO, Pedro Henrique Batista Borges (4)
}

(1) LD Engenharia, e-mail: leonardo@1dengenharia.com.br (2) Universidade Federal de Minas Gerais, email: paulo@demc.ufmg.br, (3) Universidade Federal de Minas Gerais, e-mail: cicerostarling@ufmg.br,

(4) LD Engenharia, e-mail: viperpedro95@gmail.com

\begin{abstract}
Public projects present recurring problems of quality, cost overruns and delays, as widely reported in recent research works. In this context, the legal framework of the Differentiated Regime of Contracting $(R D C)$ was created, which has been the object of criticism and controversy due to its juridical peculiarities. However, there are still few studies in Brazil that evaluate the impact of the RDC from the technical point of view. The present work aims to contribute with the analysis of the RDC aspects in a technical context, focusing issues related to the role of design coordination processes in the integration of design and construction phases. The research was carried out using multiple case studies, and one of them is presented. Case study sources embraced design analysis, bid and project documents, as well as direct observation of working routines. The results point out to the fact that the RDC contracting mechanisms may allow a better integration of design and execution phases, and the main aspects of coordination mechanisms are outlined and discussed. The research works contributes to a better understanding of concurrent engineering and design - construction integration on new contracts of public projects.
\end{abstract}

Keywords: RDC, Project Coordination, Public Works.

\section{INTRODUÇÃO}

Obras públicas apresentam problemas recorrentes de qualidade, aditivos de custos e prazos, conforme amplamente reportado na literatura recente. Nesse contexto, foi criado o marco legal do RDC, o Regime Diferenciado de Contratações, que vem sendo objeto de críticas e de polêmicas, em especial por questões éticas e jurídicas. No entanto, ainda são poucos os estudos no Brasil que avaliam o impacto do RDC do ponto de vista técnico, pois a maior parte dos trabalhos concentra sua atenção em aspetos legais do modelo de contratação. O presente trabalho pretende contribuir para uma análise dos aspectos do RDC em um contexto técnico. Será apresentada parte dos resultados de um projeto de pesquisa mais amplo, que avalia, por meio de estudos de caso múltiplos, em projetos de infraestrutura ferroviária. aspectos da integração entre a fase de projeto e obras e o papel da coordenação de projetos no desenvolvimento dos projetos e no processo de integração.

ZACARIAS, L. G.; ANDERY, P. R. P.; STARLING, C. M. D.; LOURO, P. H. B. B. Estudo de caso da aplicação do RDC em obra pública de infraestrutura. In: SIMPÓSIO BRASILEIRO DE GESTÃO E ECONOMIA DA CONSTRUÇÃO, 11., 2019, Londrina. Anais [...]. Porto Alegre: ANTAC, 2019. Disponível em: https://www.antaceventos.net.br/index.php/sibragec/sibragec2019/paper/view/369 


\section{REVISÃo BIBLIOGRÁFICA}

Por questões de espaço, o presente trabalho não descreverá o RDC, limitando-se a considerar algumas pesquisas recentes. Um dos principais avanços do RDC, de acordo com Andrade (2014), é inversão de fases no processo licitatório e a contratação conjunta de projeto e obra, garantindo maior celeridade ao processo. A possibilidade de formação de consórcios entre os participantes, de acordo com Oliveira et al. (2015), torna o sistema indispensável, para o poder público para realização do desenvolvimento nacional sustentável. Heinen (2013) comenta sobre acerca dos ganhos associados à contratação integrada no RDC e transferência de riscos ao consórcio. Sá et al. (2013) discutem quanto à ampliação da aplicação do modelo aos diversos empreendimentos de infraestrutura no país.

O RDC permite que as fases de projeto e obras sejam conduzidas pelo mesmo agente, analogamente ao modelo de Design-Build, mais estudado. Ou seja, design-build apresenta algumas semelhanças e particularidades frente ao RDC. As semelhanças consistem na forma de contratação: em ambos se contratam projeto e execução juntos, sob um único contrato (Konchar \& Sanvido (1998) apud Albuquerque et al (2015); Molenaar e Gransberg (2001) apud Albuquerque et al (2015)). Neste processo é possível subcontratar serviços ou formar consórcios com outras empresas. Entretanto, se diferencia quanto ao preço de contratação. No RDC tem-se apenas contratações a preço fixo ou global, já no design-build, tanto a preço global como também a preço unitário e administração contratada, cada um com diferentes distribuições de risco orçamentário entre os participantes.

\section{MÉTODO}

O trabalho baseia-se em estudo mais amplo composto por três estudos de caso. Um deles, referente a um empreendimento ferroviário contratado via RDC, será aqui apresentado. Os critérios para escolha dos casos foram: a) serem objeto de RDC; b) o consórcio vencedor ter efetivamente desenvolvido as etapas e projeto e obra; c) disponibilidade de informações.

O principal objeto de análise foi o processo de projeto simultâneo à execução das obras, onde se buscou identificar os principais ganhos na condução dos projetos tendo em vista as diferentes interfaces necessárias para o desenvolvimento das atividades de coordenação. Cabe destacar que os dados utilizados foram cedidos pelos executantes. As principais fontes de evidência foram o termo de referência do edital, os cronogramas de desenvolvimento de engenharia, o anteprojeto do edital, os projetos executivos de engenharia, fichas de análises de projetos dos clientes e as solicitações de alteração de projeto por parte da empresa construtora. Um dos autores participou das atividades de coordenação de projetos, com acesso a projetos e documentos associados.

\section{RESULTADOS E DISCUSSÃO}

O caso trata de um RDC para contratação de empresa para elaboração dos projetos básico e executivo e execução das obras e serviços remanescentes ao longo de $6 \mathrm{~km}$, e a implantação da grade (lastro, dormentes e trilhos) em $79 \mathrm{~km}$ de uma importante ferrovia nacional. $\mathrm{O}$ trecho de execução de infraestrutura encontrava-se, no momento da licitação, com obras parcialmente realizadas, como parte de serviços preliminares, terraplenagem, obras de arte correntes, especiais e obras complementares, além de desapropriação e resgates de sítios arqueológicos concluídos. 
Os principais agentes participantes do empreendimento eram o cliente, que contava com o apoio de uma fiscalizadora, além da projetista e três construtoras, que juntos compunham o consórcio construtor. O coordenador de projetos, pertencente ao quadro de empregados da projetista do consórcio construtor, contava com uma equipe de oito profissionais para desenvolver os projetos e executar todos os produtos (deliverables) do projeto executivo como os dados de levantamentos topográficos, geológicos e geotécnicos, projetos, relatórios, planilhas e desenhos de todas disciplinas.

Logo no início da execução dos trabalhos, o coordenador foi incluído no comitê de gestão do consórcio, o que garantia a ele presença e atuação ativa nos processos decisórios estratégicos da condução do contrato. Dessa forma, o coordenador de projetos assumiu um papel de liderança à frente do contrato e deixou de atuar apenas no âmbito da empresa projetista através da coordenação técnica de desenvolvimento dos projetos. Uma representação da estrutura do consórcio é apresentada na Figura 1.

\section{Figura 1 - Organograma do Consórcio Construtor}

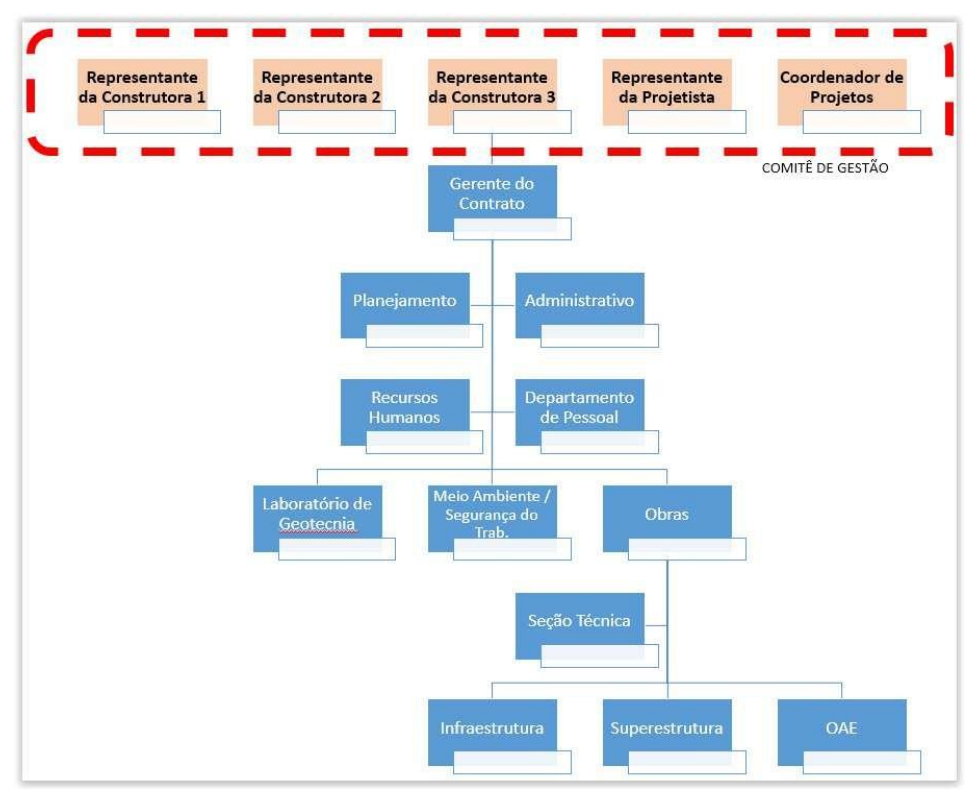

Fonte: Autores (2019)

Como consequência da atuação mais forte do coordenador, houve uma integração significativa entre projeto-obra-fiscalização. As reuniões frequentes tanto com o comitê de gestão quanto com a equipe de obra proporcionavam uma interação tanto em nível gerencial, na tomada de decisões estratégicas, quanto em nível técnico na solução de projetos.

Num primeiro momento, o ganho da integração entre projetistas e obra foi observado principalmente no desenvolvimento do projeto. A discussão acerca das soluções e dificuldades executivas proporcionou o desenvolvimento de um projeto final de execução muito mais barata que aquela solução proposta no anteprojeto do edital. Ainda que o prazo para execução do projeto estabelecido no edital de 30 dias tenha sido notadamente insuficiente para esse tipo de estudo, os resultados econômicos alcançados no projeto justificam plenamente o tempo empenhado nessa tarefa, que só foi bemsucedida devido a essa interação entre os diferentes agentes.

A redução de custos foi significativa e se reverteu em aumento de lucros ao consórcio construtor, e a adoção de métodos e soluções pouco convencionais em alguns casos para se obter esse resultado só foi possível devido ao estreito relacionamento do coordenador 
com a equipe de obras, e proporcionou ao órgão contratante uma obra com soluções mais arrojadas.

O prazo de aprovação de projetos por parte da fiscalização também teve ganhos, já que nesse aspecto, o coordenador de projetos atuou como um articulador e principal agente integrador entre as partes. Isso foi fundamental para que, ao longo de todo desenvolvimento do projeto com a construtora, a fiscalização fosse periodicamente consultada e seus analistas opinassem ativamente quanto às soluções estudadas.

Com isso, ao receber o projeto para análise, os analistas já estavam cientes das soluções de projeto e em alguns casos já tinham até sugerido soluções que haviam sido incorporadas ao projeto. Isso deixou o processo de análise e aprovação de projeto mais célere e menos conflituoso.

Os projetos foram desenvolvidos segundo alguns princípios de engenharia simultânea e apresentaram reduções significativas em alguns itens de muito peso em termos de orçamento de obras, como pode ser observado na Tabela 1.

Tabela 1 - Economia obtida no projeto

\begin{tabular}{|l|c|c|}
\hline Disciplina & Previsto em anteprojeto & Aprovado em projeto executivo \\
\hline Terraplenagem & Aproximadamente $1.385 .000 \mathrm{~m}^{3}$ & Aproximadamente $708.000 \mathrm{~m}^{3}$ \\
\hline Obras de arte especiais & $\begin{array}{c}\text { Seis viadutos, que totalizavam } \\
\text { aproximadamente } 990 \text { metros de } \\
\text { comprimento. }\end{array}$ & $\begin{array}{c}\text { Três viadutos, que totalizavam } \\
\text { aproximadamente } 522 \text { metros de } \\
\text { comprimento. }\end{array}$ \\
\hline Contenções & 633 metros lineares. & 127 metros lineares. \\
\hline
\end{tabular}

Fonte: Autor, 2018

Já na fase de obras, surgiram várias solicitações de alterações de projetos por parte da construtora, que ora sugeria soluções mais baratas, ora demandava estudos com vistas à construtibilidade. Essas alterações e revisões nos projetos não impactaram de forma significativa o andamento das obras ou dificuldades na sua execução.

Esses resultados parecem ter sido consequência da atuação ativa do coordenador de projetos no intuito de promover uma integração efetiva entre projeto e obra, inclusive com presença ativa no canteiro de obras.

Foi conduzida pelo coordenador de projetos uma nova dinâmica de desenvolvimento de projetos onde, ao invés de cada alteração feita na concepção de engenharia demandar uma completa revisão do projeto, seriam feitos estudos complementares de engenharia. Esses estudos seriam apresentados através de novos documentos de engenharia, de abordagem particularizada, com desenhos e memoriais independentes, que não invalidariam os documentos inicialmente aprovados e que seriam incorporados ao projeto completo na fase de "as built". Com isso seriam gerados pequenos volumes, que eram rapidamente desenvolvidos considerando as demandas da obra e alinhados com a fiscalização, permitindo rápida análise e aprovação.

Nesse cenário, além de a construtora ter mais controle do orçamento, o coordenador de projetos tem menos retrabalho e consegue agregar valor ao projeto, melhorando o nível de construtibilidade e reduzindo adaptações improvisadas na obra.

Claramente as ações do coordenador de projetos no caso apresentado contribuíram fortemente para a otimização da solução técnica adotada, celeridade nas alterações de 
projetos e para a redução dos custos envolvidos para os itens de maior peso orçamentário do empreendimento, maximizando os lucros entre os consorciados.

Ou seja, as evidências apontam para o fato de que uma atuação mais assertiva da coordenação de projetos foi fator essencial para a otimização das soluções de projeto.

De forma geral, o papel centralizador do coordenador e a efetividade de suas ações só foram possíveis graças à maior proximidade existente entre os agentes participantes proporcionada pelo RDC. O destaque se dá pelo fato de o RDC não ser necessariamente um modelo de contrato indutor de práticas de aumento de construtibilidade, introdução de conceitos de engenharia simultânea ou do design-build, mas por permitir uma estrutura de trabalho mais propícia para tais práticas. Os ganhos no RDC se deram mais pelos esforços do coordenador de projetos em um cenário de integração entre os agentes participantes, estando as aplicações conceituais do design-build mais associadas ao modelo organizacional de trabalho adotado pelo consórcio. E o cenário de integração dos agentes participantes no RDC é um ponto positivo frente àquilo que poderia ser proporcionado em um exemplo de aplicação da Lei $\mathrm{n}^{\circ}$ 8.666/93. Nas contratações tradicionais, o projeto é contratado separadamente da execução, de forma a limitar as possibilidades de atuação do coordenador de projetos. No entanto, o RDC de per si não garante essa integração, que depende da postura e decisão gerencial dos agentes de projeto e obras de trabalharem de maneira colaborativa.

\section{CONSIDERAÇÕES FINAIS}

O RDC é um modelo de contratação que se apresenta como alternativa ao processo tradicional regido pela Lei $\mathrm{n}^{\mathrm{o}}$ 8.666/93, possuindo semelhanças e, também, particularidades em relação ao design-build. A análise de um estudo de caso real de aplicação do RDC evidenciou, que o ambiente proporcionado pelo modelo pode contribuir positivamente para ganhos para o empreendimento em diferentes esferas, embora o modelo por si só não garanta essa integração. A atuação do coordenador de projetos se mostrou fundamental para potencialização dos benefícios que podem ser alcançados por meio da integração entre projeto e obra no RDC.

\section{REFERÊNCIAS}

ANDRADE, L.R. Ampliação do RDC é um avanço necessário nas contratações.

Revista Consultor Jurídico, 13 de maio de 2014, 13 h37.

OLIVEIRA, H. A., PESSOA NETO, J. A., BRAZ. R. T. Regime diferenciado de contratações públicas (RDC) e a eficácia do regime de contratação integrada das obras públicas: experiência INFRAERO. VIII Congresso CONSAD de Gestão Pública. Brasília, DF, 2015.

HEINEN, J. A contratação integrada no regime diferenciado de contratações (Lei $\mathbf{n}^{\mathbf{0}}$ 12.462/11). Revista de Direito - Procuradoria Geral do Estado de Goiás. Goiânia, v.28, 2013.

SÁ, A. L. S. de, SANTOS, E. M., BRASILEIRO, A. Contrato de eficiência no regime diferenciado de contratações públicas: uma inovação a ser aplicada na gestão das infraestruturas de transportes. In: XXVII CONGRESSO DE PESQUISA E ENSINO EM TRANSPORTES - ANPET. 2013, Belém, Pará.

ALBUQUERQUE, A.E.C.; PRIMO, M.A.M.; PEREIRA, F.A. Vantagens, Riscos e

Desvantagens na Adoção do Método de Contratação Design-Build pelo Setor Público Brasileiro. São Paulo, 2015. Revista brasileira de gestão de negócios, v. 17, n. 54, p. 822-838. 
SIBRAGEC - ELAGEC 2019 - de 23 a 25 de Outubro - LONDRINA - PR

KONCHAR, M.; SANVIDO, V. Comparison of U.S. project delivery systems. 1998. Journal of Construction Engineering and Management, p.435-444.

MOLENAAR, K.R.; GRANSBERG, D.D. Design-builder selection for small highway projects. 2001. Journal of Management in Engineering, p.214-223. 